\title{
Blackstart from HVDC-connected Offshore Wind: Hard vs Soft Energization
}

\author{
Jain, Anubhav; Saborío-Romano, Oscar; Sakamuri, Jayachandra N.; Cutululis, Nicolaos A.
}

Published in:

IET Renewable Power Generation

Link to article, DOI:

10.36227/techrxiv.12948737.v1

$10.1049 /$ rpg 2.12010

Publication date:

2021

Document Version

Publisher's PDF, also known as Version of record

Link back to DTU Orbit

Citation (APA):

Jain, A., Saborío-Romano, O., Sakamuri, J. N., \& Cutululis, N. A. (2021). Blackstart from HVDC-connected Offshore Wind: Hard vs Soft Energization. IET Renewable Power Generation, 15(1), 127-138.

https://doi.org/10.36227/techrxiv.12948737.v1, https://doi.org/10.1049/rpg2.12010

\section{General rights}

Copyright and moral rights for the publications made accessible in the public portal are retained by the authors and/or other copyright owners and it is a condition of accessing publications that users recognise and abide by the legal requirements associated with these rights.

- Users may download and print one copy of any publication from the public portal for the purpose of private study or research.

- You may not further distribute the material or use it for any profit-making activity or commercial gain

- You may freely distribute the URL identifying the publication in the public portal 


\title{
Blackstart from HVDC-connected offshore wind: Hard versus soft energization
}

\author{
Anubhav Jain $^{1}$ (D) | Oscar Saborío-Romano ${ }^{1}$ (i) | Jayachandra N. Sakamuri ${ }^{2}$ (i) | \\ Nicolaos A. Cutululis ${ }^{1}$ (D)
}

${ }^{1}$ DTU Wind Energy, Technical University of

Denmark, Roskilde, Denmark

${ }^{2}$ Vattenfall A/S, Kolding, Denmark

Correspondence

Anubhav Jain, DTU Wind Energy, Technical University of Denmark, 4000 Roskilde, Denmark.

Email:anub@dtu.dk

Funding information

H2020 Marie Skłodowska-Curie Actions, Grant/Award Number: 765585; H2020 Energy,

Grant/Award Number: 691714

\begin{abstract}
In recent years, renewable energy sources have been integrated on a large scale in power systems all around the world to address the environmental sustainability concerns. With conventional thermal generators being phased out, large offshore wind power plants present a viable alternative to provide blackstart services for power system restoration. By means of simulations, grid-forming wind turbines are shown to successfully energize the offshore transformer and the high-voltage direct current (HVDC) export link in a controlled manner, to ultimately supply onshore block load. Two methods for energizing the offshore network have been compared: the prevalent hard-switching approach and the more complex soft-start method. Additionally, control has been implemented to mitigate the significant transients in the export link associated with pre-charging of the onshore converter. It is shown that soft-start can provide faster energization with smaller transients compared to hard-switching. Moreover, the sensitivity analyses performed in this study illustrate the impact of pre-insertion resistor and voltage ramp-up rates on transients during hardswitching and soft-start, respectively. The results presented also show that grid-forming wind power plants can deal with controlled pre-charging of the onshore converter from its DC terminals that is essential for the safe energization and operation of the export link.
\end{abstract}

\section{1 | INTRODUCTION}

According to the Global Energy \& CO2 Status Report by IEA [1], worldwide energy demand in 2018 increased at a rate unseen since 2010 , driven by the rapidly growing population and a robust global economy with higher heating and cooling needs. Increase in demand for electricity was responsible for almost half of such energy growth. Despite solar and wind growing at a double-digit pace, renewables were not able to catch up, which led to an increased use of fossil fuels. This resulted in a historically high $33.1 \mathrm{Gt}$ of global energy-related $\mathrm{CO}_{2}$ emissions in 2018, with the power sector accounting for nearly two-thirds of emission growth.

Thus, renewable energy sources are being integrated on a large scale into power grids all around the world to tackle the challenges of rising pollution levels and environmental problems related to global warming, and address sustainability concerns. The European Union's 2018 'RED IP directive on the promotion of the use of energy from renewable sources [2] sets an overall goal across the EU for a $32 \%$ share of renewables in the total energy consumption by 2030 . Along with the EU, China, India, United States and many other countries have set out decarbonization strategies for the transport and districtheating/cooling sectors in addition to the power sector, aiming to achieve a secure economy and a sustainable future. According to a recent report by International Renewable Energy Agency (IRENA) [3], the falling costs of renewables can unlock the low-cost decarbonization of energy end-use sectors by extensive electrification of passenger transport and space and water heating in buildings, increasing the share of electricity in the total final energy consumption to $68 \%$ by 2050 , compared to $19 \%$ today. These measures coupled with the phasing out of conventional thermal generation units show huge promise for renewable-generated electricity as the fuel of the future.

Since its humble beginnings in the early 1990s, wind energy has seen a rapid growth in its installed capacity worldwide,

This is an open access article under the terms of the Creative Commons Attribution License, which permits use, distribution and reproduction in any medium, provided the original work is properly cited.

(C) 2020 The Authors. IET Renewable Power Generation published by John Wiley \& Sons Ltd on behalf of The Institution of Engineering and Technology 
making onshore wind, along with hydropower, one of the cheapest sources of electricity around the world, with associated costs now at the lower end of the fossil-fuel range [3]. Offshore wind installations in 2018 totalled 4.5 GW, although almost exclusively in the EU and China, bringing the global levelized cost of energy (LCoE) to $0.127 \mathrm{USD} / \mathrm{kWh}$, with estimates of around $0.06-0.10 \mathrm{USD} / \mathrm{kWh}$ by 2022 , at least in the EU [3]. Offshore wind in Europe currently surpasses $20 \mathrm{GW}$ (installed capacity) and covers more than $1.5 \%$ of its electricity demand, but the European Commission has recently proposed 230-450 GW of offshore wind by 2050 to achieve carbon neutrality and lead the energy mix of the future [4].

However, a high volume of renewable energy in the power system poses challenges to maintaining network stability, reliability and security of supply. The introduction of variable power flows, inertial decoupling by power electronic converter (PEC) interfaces, decommissioning of synchronous generators and higher uncertainty in scheduling coming from forecasting errors can lead to over-burdened reactive power reserves, violent frequency swings and overall decreased transient stability. These factors increase the risk of wide-area blackouts due to potential cascaded tripping of large generation units and system split scenarios [5, 6]. Additionally, due to increasing penetration of renewable energy, gas and thermal plants are now being used as peaking plants for balancing. The resulting decreased average load factors raise the costs of warming-up or keeping such large generators on standby. This has led to a hike in blackstart costs in recent years and the requirement of blackstart services from other power plants to increase the operative resources during power system restoration and create new restoration corridors [7].

Offshore wind power plants (OWPPs) can be suitable candidates to support grid recovery, as modern wind turbines (WTs) can meet some of the blackstart and islanding requirements specified in network codes [8]. Larger OWPPs with larger WTs are being commissioned and developed in deeper waters, further away from shore, to harness superior wind conditions and reduce the $\mathrm{LCoE}$ through economies of scale. As a consequence, HVDC transmission technology is gaining momentum over the currently more prevalent high-voltage alternating current. HVDC transmission technology based on voltage source converters (VSC) has shown excellent voltage and frequency control performance and the potential to help reduce restoration time while facilitating a safer and smoother restoration process [9]. Denmark and Ireland already use their VSC-HVDC interconnections with Norway and Great Britain, respectively, for blackstart service [10]. Thus, HVDC-connected OWPPs with blackstart-able or grid-forming [11] type-4 WTs (interfaced by fully-rated PECs), can be expected to perform fast voltage ramp-up and tackle the challenges in energizing cables, transformers, converters and loads, while maintaining stable, synchronized parallel operation [12].

Grid-forming control of W'Ts in OWPPs was originally developed to enable the use of diode rectifiers (DRs) for connecting OWPPs to HVDC, so as to reduce costs through higher reliability and lower losses, complexity and footprints. The study in [13] shows that a DR-connected OWPP can contribute with restoration services for onshore grids by smoothly energizing the HVDC grid, including rectifier transformers, reactive compensation and filter banks, submarine cables and onshore converter capacitors without the need of limiter resistors. Simulations presented in $[14,15]$ show that it is also theoretically possible for an HVAC-connected OWPP with droop-controlled WTs to blackstart an onshore grid through an HVAC export cable, with the success of the various energization stages depending very much on the WT grid-side converter (GSC) grid-forming control and the electrical system design, ensuring that there is enough turbine capacity to absorb the reactive power generated by the cable section to be energized.

For an HVDC-connected OWPP to successfully provide green blackstart service during power system restoration, it must be able to deal with the reactive power requirements of interarray cable energization, withstand the transformer magnetic inrush currents, especially those from the large HVDC transformer, and stably operate the offshore island to ultimately cater to onshore block loading after energizing the HVDC export link. A 400 MW OWPP in a 1 GW cluster connected via a $200 \mathrm{~km} \pm 320 \mathrm{kV}$ HVDC link is shown in [16] to blackstart an onshore load after dealing - in a controlled manner - with transformer and cable energization transients during hard-switching with a pre-insertion resistor (PIR). However, the energy imbalance in the HVDC link during the uncontrolled pre-charging of the onshore converter cells from its DC terminals leads to a significant dip in HVDC voltage and large transients in the offshore and onshore converter cell voltages and valve currents. Contrary to hard-switching, restoration tests with HVDC interconnectors between two AC grids, have demonstrated that after energization from the live-side, the soft-start capability of the dead-side HVDC-VSC can significantly reduce the transients associated with transformer inrush and cable charging currents during the network energization $[17,18]$.

The main contribution of this paper is the comparison of hard-switching and soft-start energization methods for the blackstart of onshore load by an HVDC-connected OWPP with grid-forming WTs. Parametric sensitivity studies have been performed to quantify the potential impact of the PIR on the transient voltage dips and power peaks during energization of the offshore network, for the hard-switching approach - and the capability of grid-forming W's to energize the complete network at different ramp-rates, for the soft-start approach. Finally, this paper also investigates the potential of the OWPP to successfully and safely energize the HVDC export link by implementing a controlled pre-charging of the onshore converter from its DC terminals before it starts forming the onshore grid and picks up block load.

Section 2 gives a brief overview of the two energization approaches used for this study, namely, hard-switching and softstart. This is followed by the description of the model and controls used along with an explanation of the onshore converter pre-charging sequence in Section 3. Then, the simulation study conducted has been presented in Section 4 along with a discussion of the results of the entire energization sequence, onshore converter pre-charging and sensitivity analyses for the two energization approaches, closing with the main conclusions. 


\section{2 | ENERGIZATION METHODS}

This section gives an overview of the two main approaches of energization used in power system restoration in general, for both AC and DC connected networks.

\subsection{Hard switching}

The typical restoration approach is sequential hard-switching in which all critical transmission network components like cables and transformers are connected and energized in sections at rated voltage via $\mathrm{AC}$ breakers in a stepwise manner, ensuring full control from a system operation point of view. However, energization of transformers is characterized by a low impedance path in the beginning, drawing in a large inrush current and hence causing a voltage dip in the system [19]. Charging of lightly loaded AC transmission lines or long AC cables with open ends causes an over-voltage - the Ferranti effect [19]. Also it is important to ensure that the generator(s) can absorb the full amount of reactive power generated by the un-/lightly loaded lines to avoid Ferranti effect [20]. Additionally, insufficient load and online generation early on can lead to low damping of loworder harmonic resonance [21]. All these combined can lead to significant transient under-voltages (TUVs) [21], transient overvoltages (TOVs) [22] and slow front over-voltages (SFOs) [19], which can be difficult on control stability, damage passive components like insulators, reactors and arresters, due to higher electrical stress, and increase the risk of tripping of power electronic devices.

Different methods have been proposed in literature for mitigating such transients. The most straightforward method is controlled energization, in which the generator terminal voltage is kept at around $95-97 \%$ of its rated value. This reduces the maximum core flux in the incoming transformer due to core-design reserve [23]. The method has been demonstrated to limit the inrush current and sympathetic interaction between transformers during the worst-case scenario of energization of the farthest W'T transformer by the offshore auxiliary diesel generator in an HVDC-connected OWPP [24].

The most advanced method to mitigate high inrush currents especially for large transformers is point-on-wave switching (PoWS), which calculates the proper instant of energization by monitoring the instant of de-energization and calculating the residual flux in the core. For three-phase units, a delayed closing strategy is used to connect at an optimal instant by treating the transformer as a single-phase core, leading to no inrush [23]. The Smart Energize method has also been proposed in [23], which uses a $5 \mathrm{~V} \mathrm{DC}$ voltage source to set the residual flux instead of measuring/calculating it and connecting the transformer at a fixed angle. This constitutes a simple, highly efficient, reliable and cheap solution to limit the inrush currents to $1 \mathrm{pu}$. This prefluxing technique mitigates the inrush current to a value lower than PoWS which requires knowledge of the residual flux in the phase, that can be quite tedious to acquire for a three-phase power transformer [25].
The transient mitigation method considered for the purpose of this study is to artificially increase the impedance of the source feeding the transformer by switching in a PIR and then bypassing it after a certain time once the energization is complete. In addition to reducing voltage dips very efficiently, a PIR - being passive - offers reduced complexity and savings in maintenance cost compared to an additional independent poleoperation circuit-breaker - an active device - required for PoWS, to separately switch and correctly energize the offshore transformer and converter cells. Moreover, the AC circuit breaker required in PoWS is a mechanical equipment which includes an uncertainty in closing delays. This needs to be accounted for in a statistical manner in a design study, as shown in [26], to cover the worst-case scenario.

\section{2 | Soft start}

A different strategy for restoration is to connect the different parts of the AC network like cables, reactors and transformers, together with the black-starting generator at low voltage and smoothly ramp-up the voltage of the entire network to energize it in one step. Such soft-start greatly reduces the inrush currents and minimizes the risk of over-voltage problems while speeding up the restoration process [17]. The first soft-start energization was performed on the INELFE link between France and Spain, since RTE's specifications provided such requirements [27]. Top-down restoration tests with the Skagerrak 4 (between Norway and Denmark) [17] and the NEMO Link (between the United Kingdom and Belgium) [18] VSC-HVDC interconnectors show that soft-start by VSCs is extremely useful for eliminating transformer inrush effects, avoiding significant harmonic TOVs and reducing the probability of system re-collapse.

During hard-switching energization by VSC-HVDC networks, each switching action creates inrush currents and voltage fluctuations that the HVDC must control, damp and ride through, in addition to the risk of resonance getting excited and existing protections tripping. Damping controls on the HVDC VSCs are thus needed unless other measures are implemented. Contrarily, soft-start presents no risk of protection maloperation due to negligible inrush current, but delayed fault clearance is likely, and there is a risk of resonance getting excited due to sudden post-fault voltage recovery [28].

The question over which method is more advantageous does not seem to have an answer yet. While hard-switching, with its sequential and bounded nature, allows for an easier detection of a failed component, high transient currents drawn during energization of islanded offshore networks can cause high electromagnetic torque oscillations and high torsional stresses in WT generator shafts, which could lead to fatigue and failure [19]. On the other hand, recent results presented in [29] validate - from a generator perspective - control aspects of self-energization and blackstart capability of a type-4 gridforming W'T in turbulent/extreme wind conditions, through test benches using co-simulation and hardware-in-the-loop methodologies, showing that soft-start significantly reduces the 


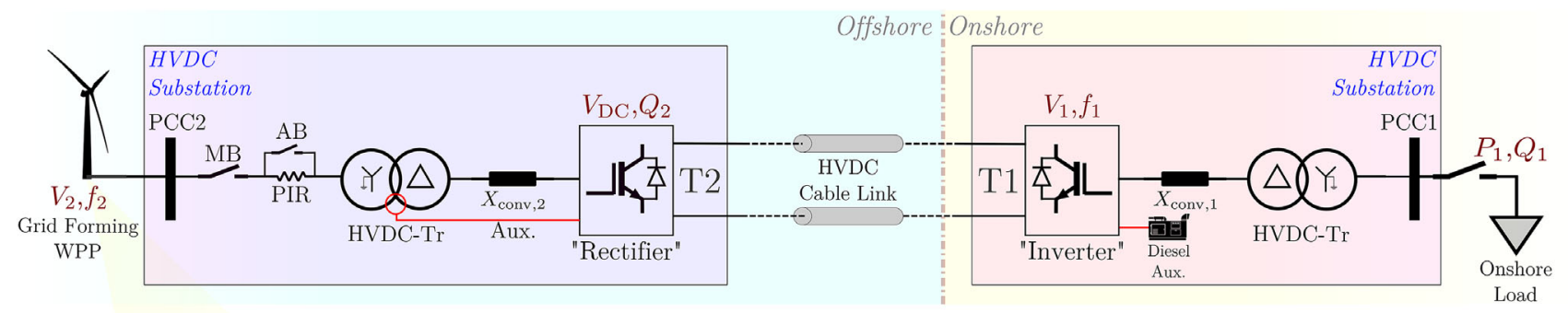

(a)

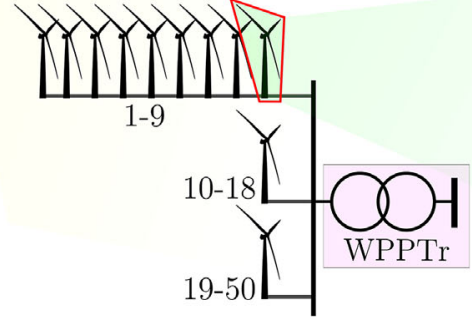

(b)

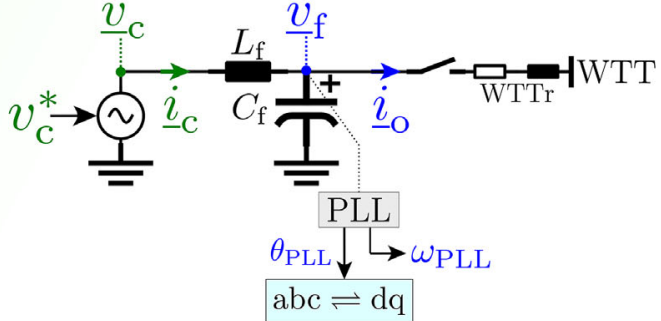

(c)

FIGURE 1 Schematic of the implemented PSCAD model of the system under study (a) Point-to-point HVDC link, with grid-following offshore terminal and grid-forming onshore terminal. (b) Partially aggregated offshore wind power plant representation. (c) Grid-forming wind turbine grid-side network.

current and voltage stresses on electrical equipment. However, careful design and testing is needed for a practical implementation as soft-start increases practical complexity due to increased requirement of auxiliary power while reduced-voltage energization is done [19]. Moreover, due to the low short circuit levels during energization, fault clearing is dependent on the backup protection in the form of distance or under-voltage trip relays, and so different protection settings are required during soft-start. This results in no selectivity for some critical faults and increases the likelihood of delayed fault clearance with the risk of resonance excitation due to sudden/fast post-fault voltage recovery. Such risk may be acceptable, as the blackstart sequence can be restarted if/once such faults are cleared, although resulting in longer restoration times.

\section{3 | MODEL DESCRIPTION AND CONTROL}

Figure 1 shows an overview of the system under study. The model has been developed in PSCAD and is based on those described in $[16,30,31]$. It consists of a 400 MW OWPP with grid-forming WTs, connected to an onshore AC grid by means of a $200-\mathrm{km}$-long $1200 \mathrm{MW} \pm 320 \mathrm{kV}$ symmetrical monopolar point-to-point HVDC link, as shown in Figure 1(a). The system parameters have been tabulated in Appendix A.

Detailed equivalent models [32] are used to represent the half-bridge modular multilevel converters (MMCs) in both terminals of the HVDC link. A frequency-dependent (phase) model is used to represent the HVDC export cable and a detailed magnetic model (including inrush and saturation) is

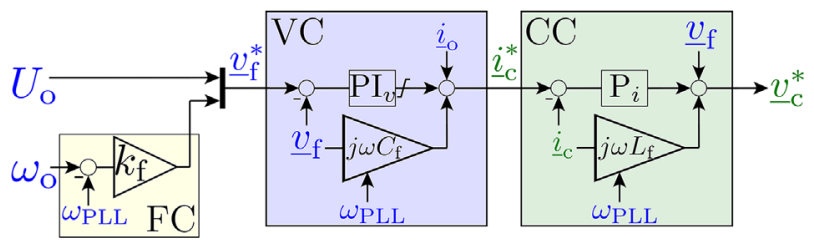

FIGURE 2 Grid-forming wind turbine grid-side converter control with cascaded voltage (VC) and current (CC) control loops and PLL-based frequency controller (FC)

used to represent the 66/390 kV HVDC transformer. Finally a PIR is used for limiting the transient magnetic inrush current peak during hard-switching energization of the HVDC transformer. The PIR is inserted by closing the main breaker (MB) and bypassed by closing the auxiliary breaker (AB) after a given pre-insertion time (PIT). For soft-start $\mathrm{MB}$ and $\mathrm{AB}$ are kept closed from the beginning.

The OWPP consists of 50 type-4 (fully rated PEC interface) 8 MW WTs, represented with the partially aggregated model shown in Figure 1(b), using the method described in [33]. It consists of WTs 1-9 represented individually in the first string, WTs $10-18$ in the second string aggregated into a $72 \mathrm{MW}$ equivalent WT model, and the remaining WTs 19-50 aggregated into a 256 MW equivalent WT model. Coupled $\pi$-section models are used to represent the $66 \mathrm{kV}$ array cables. Lastly, each WT is modelled as a grid-forming unit operating in islanding mode. The WT grid-side network is depicted in Figure 1(c). Each W'T GSC is modelled as a voltage source (average model) controlled by the grid-forming control strategy shown in Figure 2. This control is based on that in [16,34] and consists of an outer frequency control loop based on the phase-locked loop (PLL) with cascaded 
voltage and current control loops in a synchronous rotating (dq) reference frame, commonly used in converter control.

\subsection{Assumptions}

The model described above has certain simplifications. Firstly, the WT rotor-side converter (RSC) and changes to the turbine controller that are required for grid-forming operation, have not been modelled. In conventional grid-following operation of the W'T, the RSC is controlled to extract maximum power from the generator while the GSC maintains power balance to regulate the DC link voltage of the back-to-back PEC interface of the W'T and the reactive power output at the AC terminal. However, in grid-forming mode, the GSC cannot control the DC link and reactive power anymore, and the required generator torque and real power is set by the AC load, not the turbine controller, which now has to regulate the speed using the pitch controller - and especially avoid over-speeding during low AC load and high winds. Hence, the RSC control requires changes to be able to maintain the DC link voltage constant by ensuring active power balance [29]. The implications of this redesign required in the rotor speed controller - to operate stably at very low active power levels, cope with sudden changes in generator torque during large load steps, and to prevent transient over-speeding of the WT during load disconnections in the weak grid conditions of a blackstart scenario - are discussed in [35].

Since the WT rotor and DC link dynamics are outside the scope of the study, constant WT DC link voltage (ideally controlled by the RSC) is assumed. An average voltage source model is used for the GSC, and dynamics faster than the bandwidth of the inner current control loop, designed to $200 \mathrm{~Hz}$, are out of the scope of this study. Moreover, each W'T transformer is represented by its equivalent leakage impedance (no magnetic characteristics), as it is much smaller than the HVDC transformer and can be soft-started along with the WT voltage ramp-up, to avoid magnetic inrush and saturation effects. Furthermore, since dynamics inside the OWPP are not the main focus, outer power sharing loops in the WT controls are not considered, and the WTs start operation simultaneously. Additionally, no auxiliary loads are considered, resulting in minimum system damping and more demanding energization transients.

\section{2 | HVDC converter control and pre-charging}

The converter at the offshore terminal ('Rectifier') is controlled in grid-following mode, since the offshore AC network voltage is formed by the grid-forming WTs in the OWPP. Such converter thus regulates the HVDC link voltage $V_{\mathrm{DC}}$ and reactive power injection $Q_{2}$ into the offshore AC network, as described in [16]. The converter in the onshore terminal ('Inverter') is controlled with a simple grid-forming scheme, shown in Figure 3, to regulate the onshore AC network voltage magnitude $V_{1}$ and frequency $f_{1}$, in the scope of the blackstart case study performed.

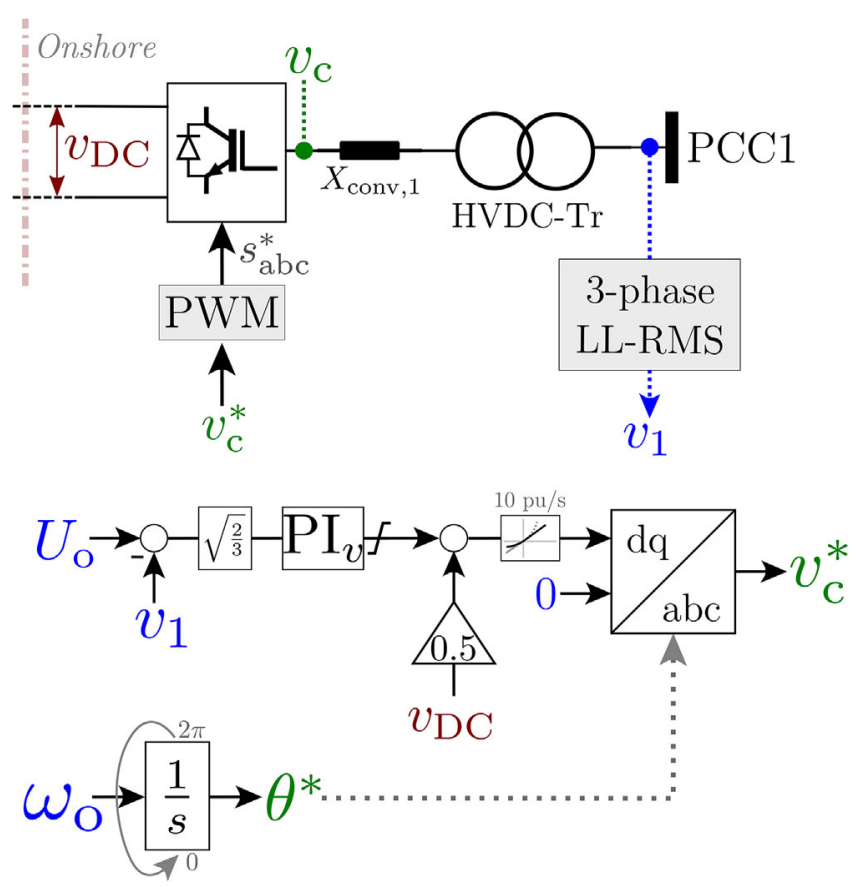

FIGURE 3 Onshore MMC AC voltage control for islanded operation

The MMCs use standard inner control loops, such as cell voltage balancing and circulating current suppression.

Conventionally, the onshore MMC cells are pre-charged from the onshore AC grid, and the offshore MMC cells are precharged uncontrollably by a diesel generator, once the HVDC link voltage is stabilized [36]. This diesel unit is typically co-located on the offshore HVDC substation as backup emergency supply and for supplying auxiliary load to be ready-for-energization [36]. However, in the scope of this study, the WT's are supposed to energize the offshore AC network and HVDC link to supply the onshore block load, without relying on other components or networks for MMC cell pre-charging. Since the startup direction is reversed to that in [36], the offshore MMC is pre-charged from the $\mathrm{AC}$ voltage formed by the OWPP, while the onshore MMC from its DC terminals connected to the HVDC link. An onshore diesel generator - as shown in Figure 1 - is assumed to provide the auxiliary power, which if offshore, is very costly in terms of space occupied, maintenance and safety requirements, and insurance.

In [16], onshore MMC cell charging starts only when the converter begins forming the onshore AC network voltage (with its cells de-blocked) due to the lack of a pre-charging control. This results in an energy imbalance in the HVDC link during the DC-side charging of the onshore MMC cells, which leads to large transients in cell voltages and valve currents, and a significant dip in the HVDC link voltage. The reason for this is that, at the end of HVDC link energization by the offshore MMC (Stage 3), the $640 \mathrm{kV} \mathrm{HVDC}$ link voltage is divided equally between 450 capacitors (225 per arm) in the whole leg, charging them uncontrollably to $1.42 \mathrm{kV}$, which is only half of the nominal $2.85 \mathrm{kV}(=640 \mathrm{kV} / 225)$. So, when the converter is de-blocked, its submodules (now only 225 inserted in total 


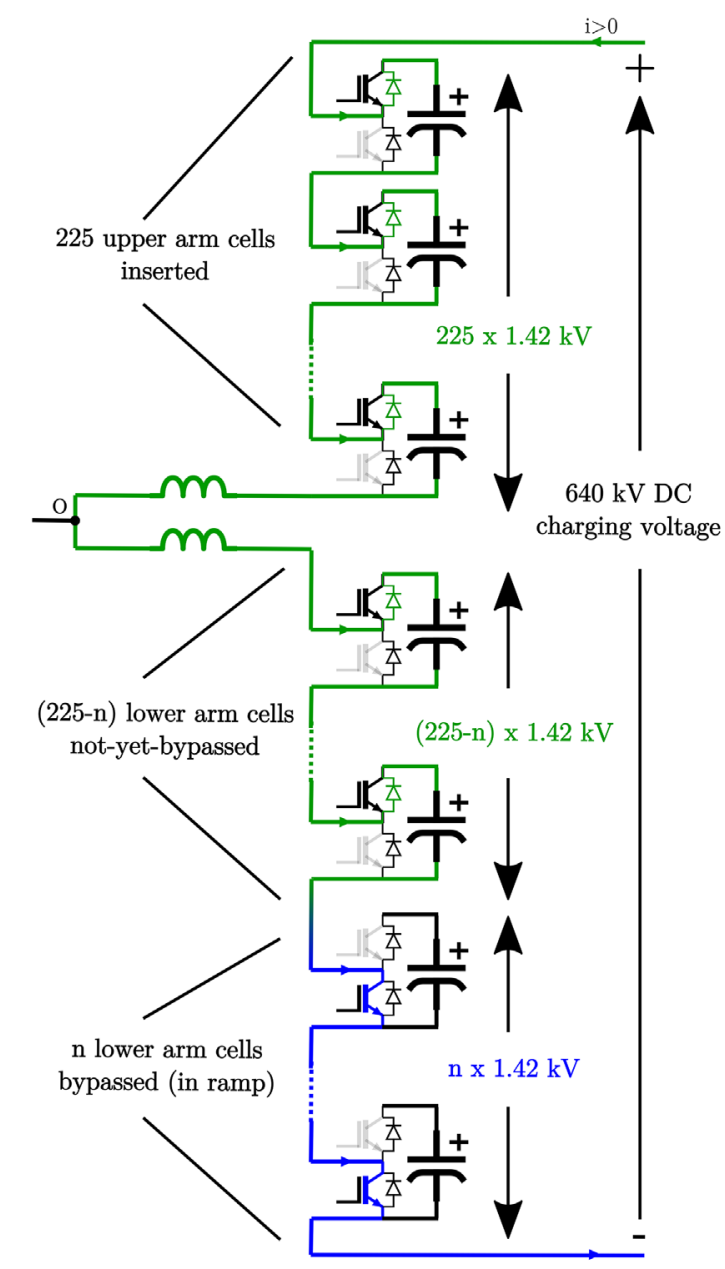

(a)

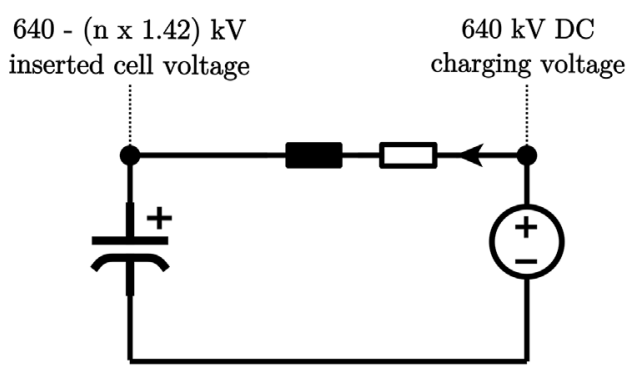

(b)

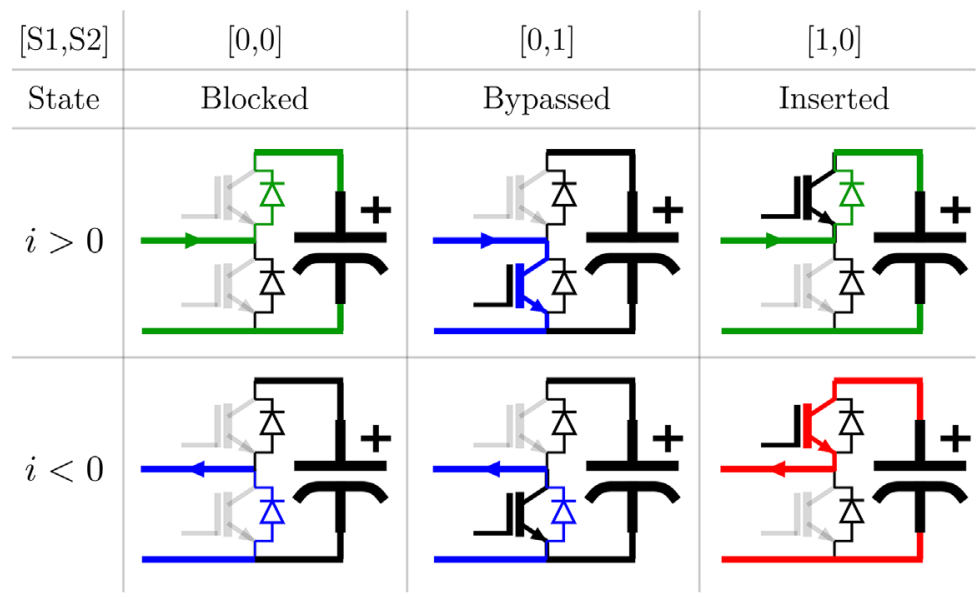

(c)

FIGURE 4 Controlled pre-charging of onshore MMC cells (a) Pre-charging of upper arm, with ramp-controlled bypass of lower arm cells. (b) Simplified equivalent circuit for (a). (c) Submodule operating states depending on switching configuration: the cell capacitor charges (green), discharges (red) or holds the charge (blue) depending on the operating state and current direction.

in a leg, at any time) charge uncontrollably from $1.42 \mathrm{kV}$ (total inserted voltage of $320 \mathrm{kV}$ ) to the desired nominal cell voltage of $2.85 \mathrm{kV}$ from the DC side $640 \mathrm{kV}$, drawing large charging currents with simultaneous dis-charging due to submodules being switched to form the onshore AC network voltage. In quest of improving such transient responses, open-loop controlled pre-charging, illustrated in Figure 4, has been implemented to charge the onshore MMC submodule capacitors to the nominal $2.85 \mathrm{kV}$ before the converter is de-blocked and begins forming the onshore AC network.

Different methods for MMC pre-charging have been proposed in literature. While some rely on an external DC voltage source and additional switches increasing cost and complexity [37], others use the main DC link with an external resistance to limit the charging and discharging currents [38]. More complex strategies have also been proposed, where the duty cycle of one 'pulse width modulation mode' module and the number of inserted submodules is gradually decreased [39]. This allows simultaneous charging of the upper and lower arm cells with no impact from the AC load and effectively suppresses the surge current. Finally, a generalized AC/DC-side soft-startup method has been proposed in [40] that controls the charging current by adjusting the rate of number of blocked and bypassed capacitors, in conjunction with the conventional capacitor voltage sorting algorithm.

In this study, however, a simple pre-charging strategy - without any current-limiting resistance and based on [38, 40, 41] has been used and is described as follows:

1. At first, the upper arm is inserted and the lower arm bypassed, so as to fully charge all 225 cells in the upper arm. To control the charging current (and the resulting transients in the HVDC link), the lower arm cells are bypassed in small steps, instead of all at once, i.e. a ramp $(n: 0 \rightarrow 225)$. The 225 upper arm cells are thus charged in a smooth manner, from $1.42 \mathrm{kV}$ to the nominal $2.85 \mathrm{kV}$, as the partially charged 'notyet-bypassed lower arm cells add to the insertion voltage and limit the charging current. This is explained in Figure 4(a), while a simplified equivalent circuit diagram is shown in Figure 4(b). 
TABLE 1 Simulation events of the hard-switching energization sequence

\begin{tabular}{lll}
\hline Stage & Time (s) & Events \\
\hline 1 & 0 & WTs are energized simultaneously and operate in grid-forming mode. \\
2 & $t_{\mathrm{MB}}=1.3$ & MB is closed to insert PIR for energizing the offshore transformer and pre-charging the offshore MMC cells. \\
& $t_{\mathrm{MB}}+\mathrm{PIT}$ & PIR is bypassed by closing AB. \\
3 & 2.1 & Offshore MMC is de-blocked to control the HVDC link voltage; HVDC link is energized \\
4 & 2.5 & (a) Controlled pre-charging of onshore MMC's upper arm cells with lower arm bypassed. \\
& (b) Controlled pre-charging of onshore MMC's lower arm cells with upper arm bypassed. \\
5 & (c) Controlled pre-charging of onshore MMC finished; both arms blocked. \\
6 & Onshore MMC is de-blocked to control the onshore AC network voltage; PCC1 is energized. \\
\hline
\end{tabular}

2. Then, the upper arm is bypassed and the lower arm inserted, so that the upper arm cells hold their charge while the lower arm cells charge fully.

3. Lastly, both the upper and lower arms are blocked (the now fully charged cells hold their charge), before the converter is de-blocked to control the onshore AC network voltage.

Figure 4(c) shows the cell capacitor charging status for the different submodule switching states, namely, blocked, bypassed and inserted, as a function of the switching configuration and the current direction, similar to in [39]. The aforementioned approach is open-loop, which can be replaced with closed-loop control to regulate the AC/DC-side pre-charge current for reduced start-up time and no inrush peak [42]. However, not only does this require complex and specially designed algorithms for capacitor balancing and reference generation, but also a fast transition between startup and the normal operation to avoid capacitors overcharging. Alternatively, averaging capacitor voltage control with feed-forward has been shown to achieve a fast dynamic response without compromising the system stability margin and the implementation complexity [43].

\section{4 | SIMULATION STUDY AND RESULTS}

The offshore network is energized using the two different approaches, namely, hard-switching and soft-start.

The hard-switching energization sequence is summarized in Table 1. In this sequence, the HVDC transformer and converter are connected to the grid-forming OWPP at rated voltage with a PIR that is bypassed after a PIT to limit the inrush currents. The offshore MMC ('Rectifier') is pre-charged from its AC side while the onshore MMC ('Inverter') from its DC side with an additional controlled pre-charging stage (Stage 4) that is explained in Section 3.2. Finally, the onshore MMC is de-blocked to control the onshore grid voltage and pick up a $30 \mathrm{MW}$ block load. For the hard-switching case, a sensitivity analysis has been done for PIR $=\{100,200,300\} \Omega$ and PIT $=\{0.01,0.1,0.2\} \mathrm{s}$.

In the soft-start energization sequence, summarized in Table 2, the WTs smoothly ramp-up the voltage of the entire offshore AC grid, with the HVDC transformer and offshore
TAB LE 2 Simulation events of the soft-start energization sequence

\begin{tabular}{llc}
\hline Stage & Time (s) & Events \\
\hline 1 & 0 & All WTs are started simultaneously and \\
& operate in grid-forming mode; MB \\
& and AB are closed from the start. \\
& & WTs ramp-up the offshore AC \\
& & network RMS voltage from 0 to 1 \\
& & pu. \\
& & (same as for hard-switching in Table 1) \\
\hline
\end{tabular}

MMC ('Rectifier') connected. The onshore MMC ('Inverter') is pre-charged from its DC side, as in the hard-switching case, and is then de-blocked to control the onshore AC network voltage, ultimately picking up a $30 \mathrm{MW}$ block load. For the softstart case, a sensitivity analysis has been done for the ramprate expressed in time to ramp-up from 0 to $1 \mathrm{pu}, t_{\mathrm{ramp}}=$ $\{0.5,1,2\} \mathrm{s}$.

In the following, first the simulation results for the complete hard-switching energization sequence are presented. Then, the transients during the controlled pre-charging of the onshore converter cells are focused upon and compared with those in [16]. Finally, the results of the sensitivity analyses, with different PIR and PIT values for hard-switching and different ramp-rates for soft-start, are discussed.

\subsection{Complete energization sequence}

The waveforms during the complete hard-switching energization sequence are shown in Figure 5 with the time instants marking the different stages as listed in Table 1 . These results are based on those in [16] using PIR $=120 \Omega$ and $\mathrm{PIT}=0.3$ $\mathrm{s}$, with the additional controlled pre-charging of the onshore MMC described in Section 3.2. At $1.3 \mathrm{~s}$, the offshore HVDC transformer is energized, visible from the transient power peak along with a steady rise of the HVDC link voltage that is associated with the uncontrolled AC side pre-charging of the offshore MMC cells. After this the DC link voltage control by the offshore MMC is started at $2.1 \mathrm{~s}$. Then HVDC link voltage dips 

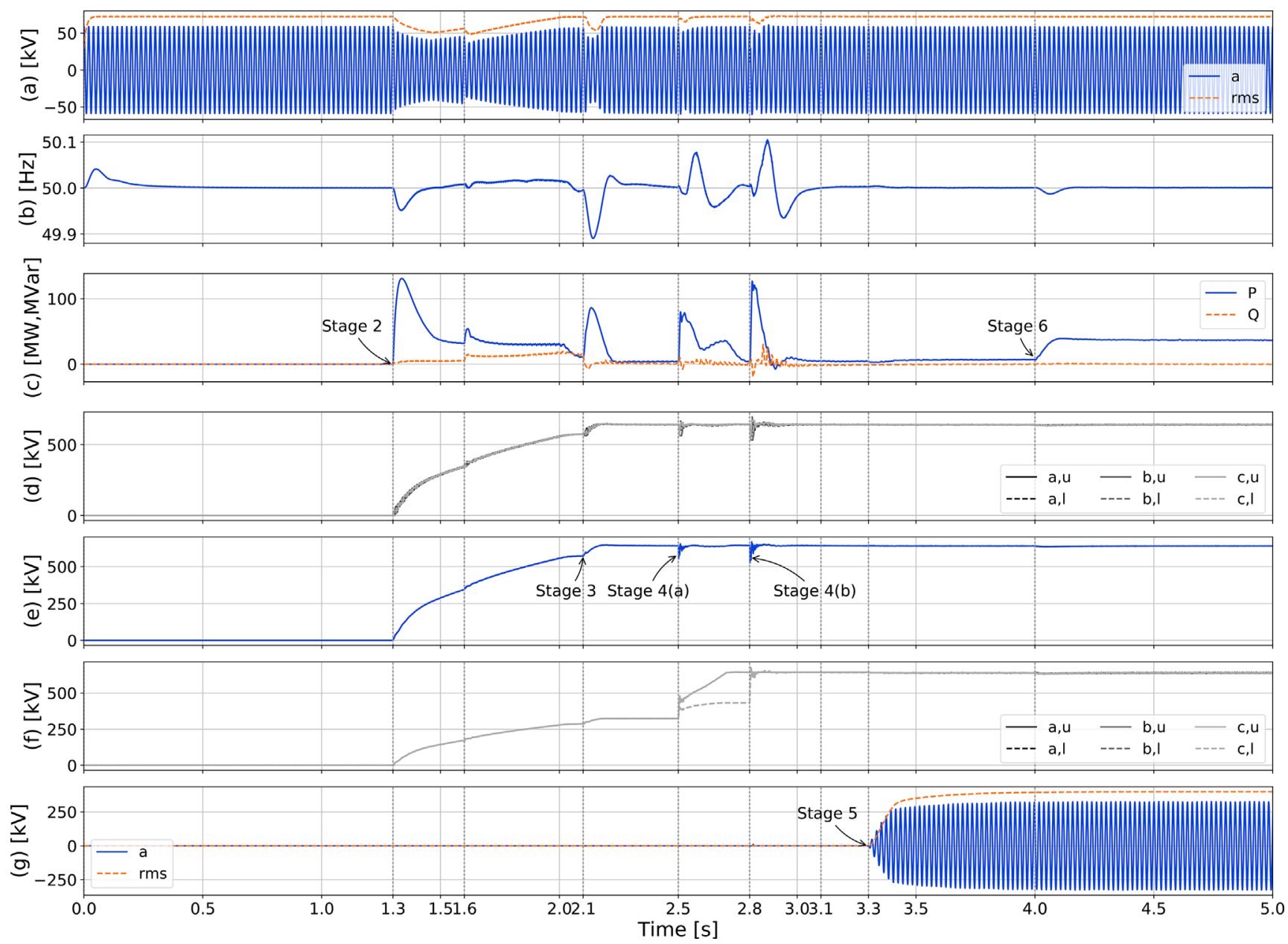

FIGURE 5 Complete hard-switching energization sequence, stages of which are given in Table 1. This figure shows (a) WPP instantaneous (blue) and RMS (orange) voltage, (b) WPP frequency, (c) WPP real (blue) and reactive (orange) power output, (d) offshore MMC sum of capacitor voltages (upper/lower arm of each phase-leg), (e) HVDC link voltage, (f) onshore MMC sum of capacitor voltages (upper/lower arm of each phase-leg), and (g) instantaneous (blue) and RMS (orange) onshore AC voltage

are seen at $2.5 \mathrm{~s}$ and $2.8 \mathrm{~s}$, associated with the controlled precharging of the onshore MMC. Finally, the onshore AC voltage control by the onshore MMC begins at $3.3 \mathrm{~s}$ and a $30 \mathrm{MW}$ onshore block load is picked up at $4 \mathrm{~s}$.

\subsection{Onshore MMC controlled pre-charging}

The controlled DC-side pre-charging stage for the onshore MMC prevents the significant HVDC link voltage dip and the disturbance in the offshore MMC cell voltage, as shown in Figure 6. The results from [16], without any pre-charge control, are also presented for comparison. In such a case, when the converter is de-blocked, the onshore MMC cells start charging uncontrollably from $1.42 \mathrm{kV}$ to the nominal $2.85 \mathrm{kV}$ while they are being switched to form the onshore AC network voltage. The resulting energy imbalance in the HVDC link causes the discharge of the offshore MMC cells to supply the charging current drawn by the onshore MMC cells, as shown in Figure 6(a). This leads to a significant drop in the HVDC link voltage, down to $320 \mathrm{kV}$, as shown in Figure 6(b). The offshore MMC, in $V_{\mathrm{DC}^{-}}$
$Q_{2}$ control mode, then reacts to such disturbance so as to bring the voltage back to the reference $640 \mathrm{kV}$, causing large oscillations in the HVDC link voltage (with a peak of up to $1000 \mathrm{kV}$ ) and the offshore MMC cell voltages and valve currents. Such disturbances in turn cause large dips/distortions in the offshore AC network voltage and oscillations in OWPP active and reactive power output, as can be seen in Figure 6(b).

As illustrated in Figure 6(a), when the controlled pre-charging stage of the onshore MMC is included, the oscillations in the offshore MMC cell voltages and valve currents along with the HVDC link voltage dip are greatly reduced. The HVDC link voltage drops to $550 \mathrm{kV}$ but then recovers quickly as a result of the offshore MMC controls. From $2.5 \mathrm{~s}$ to $2.7 \mathrm{~s}$, the upper arm is charged in a ramp, which limits the disturbance in the voltage of the offshore MMC cells, as they are discharged to supply the onshore MMC cell charging currents. This is accompanied with a power surge from the WPP, to maintain the offshore network voltage, as is shown in Figure 6(b). A similar response is observed when the lower arm cells are charged, between $2.8 \mathrm{~s}$ and $3.1 \mathrm{~s}$. Once pre-charging is complete, both arms are blocked at $3.1 \mathrm{~s}$. 

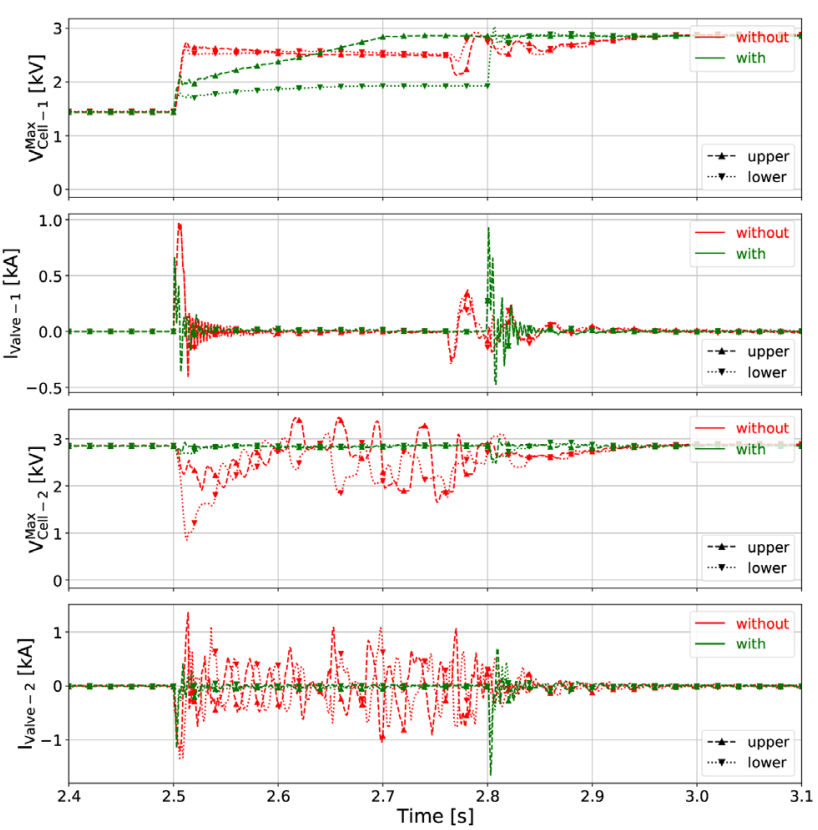

(a)
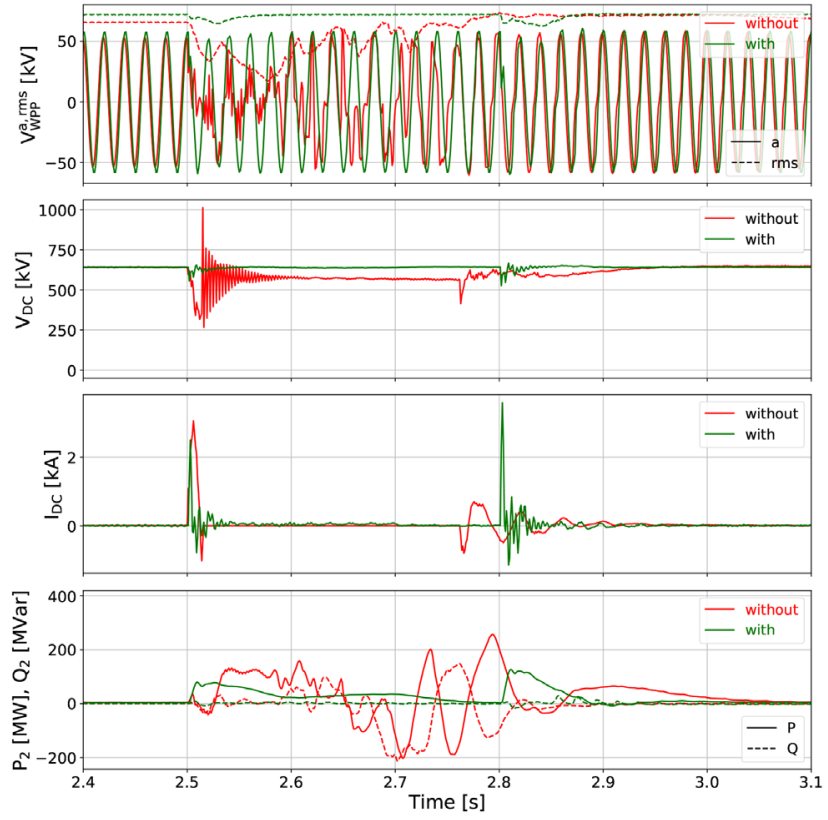

(b)

FIGURE 6 Transient responses with (green) and without (red) controlled DC-side pre-charging of the onshore MMC (a) Upper and lower arm maximum cell voltages and valve currents in the onshore (PCC1) and offshore (PCC2) MMCs. (b) WPP instantaneous (solid) and RMS (dashed) voltage, HVDC link voltage and current and WPP active (solid) and reactive (dashed) power output.
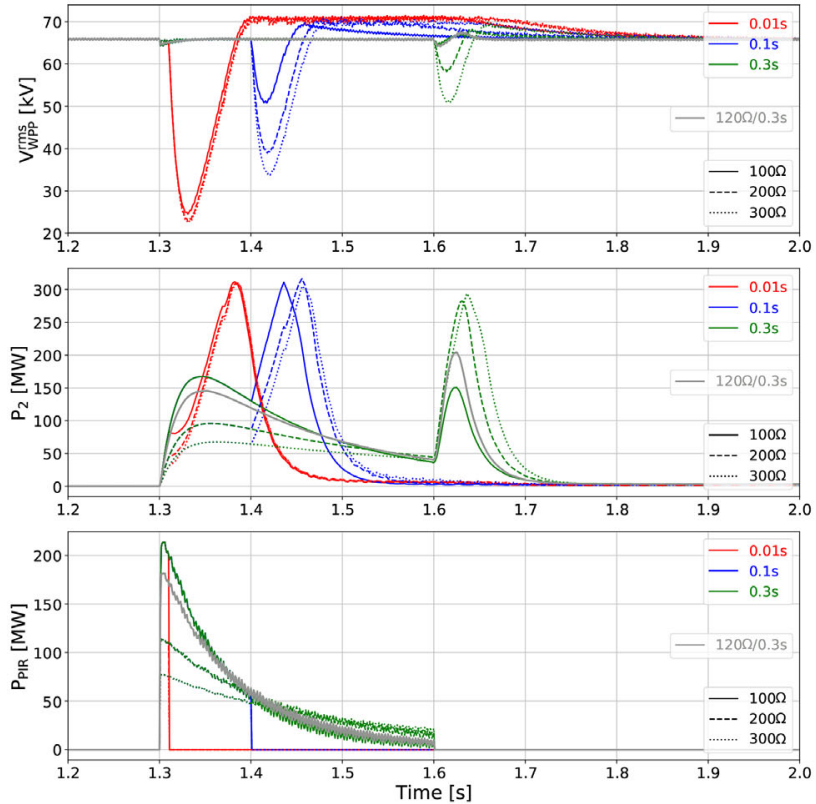

(a)
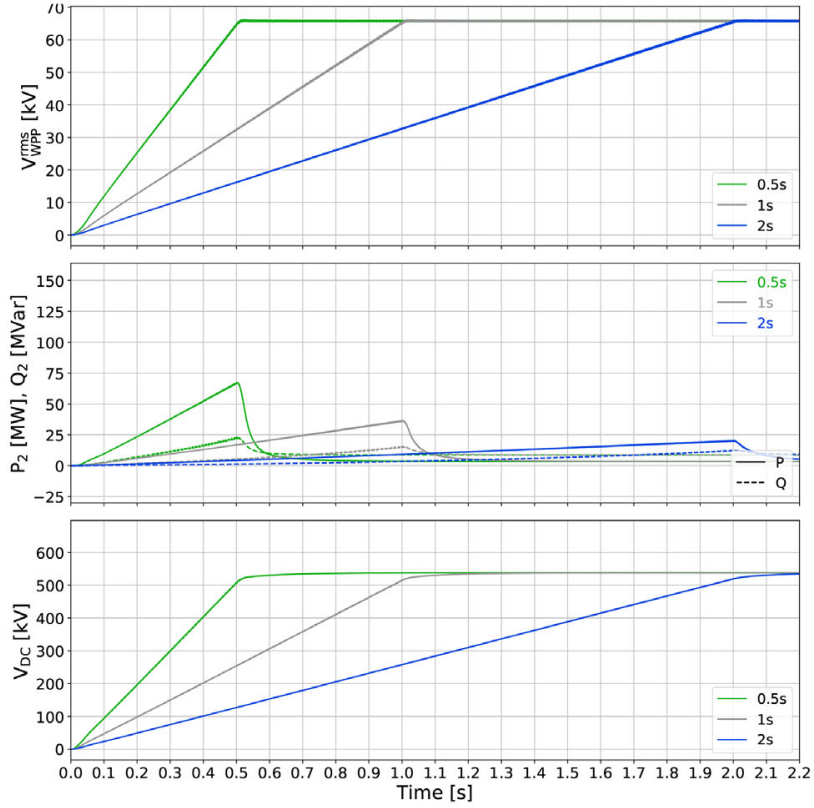

(b)

FIGURE 7 Results of the sensitivity analyses (a) Hard-switching: WPP RMS voltage, WPP active power output and active power dissipated by the PIR during the PIT interval. (b) Soft-start: WPP RMS voltage, WPP active and reactive power output and HVDC link voltage for different energization/voltage ramp-rates.

\subsection{Sensitivity analyses}

\subsection{1 | Hard switching}

Figure 7(a) shows the WPP RMS voltage, WPP active power output and active power dissipated by the PIR during the PIT interval, for different values of PIR (indicated by different line styles) and PIT (indicated by different colours). As can be observed, a transient active power peak and associated voltage dip occur when the MB is closed to energize (with the PIR inserted) the downstream network. A second transient active power peak and a much more significant voltage dip then ensue, 
TABLE 3 Transient WPP active power output peak, $P_{2}^{\text {peak }}$, and associated terminal voltage dip, $V_{\text {WPP }}^{\text {dip }}$, in per unit (base values: $400 \mathrm{MW}, 66 \mathrm{kV}$ ), for different PIR and PIT values, when PIR is inserted / bypassed, respectively

\begin{tabular}{llll}
\hline $\operatorname{PIR}(\boldsymbol{\Omega})$ & PIT $(\mathbf{s})$ & $\boldsymbol{P}_{2}^{\text {peak }}(\mathbf{p u})$ & $\boldsymbol{V}_{\text {WPP }}^{\text {dip }}(\mathbf{p u})$ \\
\hline 100 & 0.01 & $0.19 / 0.78$ & $0.97 / 0.37$ \\
& 0.1 & $0.42 / 0.78$ & $0.97 / 0.77$ \\
\multirow{3}{*}{200} & 0.3 & $0.42 / 0.38$ & $0.97 / 0.98$ \\
& 0.01 & $0.10 / 0.77$ & $0.98 / 0.35$ \\
& 0.1 & $0.24 / 0.79$ & $0.98 / 0.59$ \\
300 & 0.3 & $0.24 / 0.70$ & $0.98 / 0.88$ \\
& 0.01 & $0.07 / 0.77$ & $0.99 / 0.34$ \\
& 0.1 & $0.17 / 0.76$ & $0.99 / 0.51$ \\
& 0.3 & $0.17 / 0.73$ & $0.99 / 0.77$ \\
\hline
\end{tabular}

when the AB is closed to bypass the PIR after the PIT interval. The values of the transient WPP output power peaks and WPP voltage dips are listed in Table 3 in pu.The simulation results show that:

- The WPP terminal voltage dip when the PIR is inserted is not significant.

- Higher PIR values reduce the transient active power peaks by providing increased damping during the inrush. However, the WPP terminal voltage dips are larger, except at lower PIT values, for which the PIR does not influence the voltage dip.

- Smaller PIT values lead to lower transient active power peaks at insertion but higher ones at bypass. Additionally, the WPP terminal voltage dips to lower values, as smaller time intervals mean lesser energy dissipated, resulting in a higher voltage disturbance.

PIR and PIT values of $120 \Omega$ and 0.3 s, respectively, have been used in [16] to limit the voltage dip due to the transient active power peak during energization, as shown in Figure 7(a) in grey. However, in practice, the energy dissipated by the PIR during the PIT determines its cooling needs and duty cycle, and ultimately drives its volume/size. The energy dissipated by the PIR during the PIT interval (starting at $t_{\mathrm{MB}}=1.3 \mathrm{~s}$ ) is given by

$$
E_{\mathrm{PIR}}=3 \int_{t_{\mathrm{MB}}}^{t_{\mathrm{MB}}+\mathrm{PIT}} I_{\text {phase }}^{2} \text { PIR dt, }
$$

where $I_{\text {phase }}$ is the phase RMS current flowing through the PIR. Figure 8 portrays $E_{\text {PIR }}$ as a function of PIR and PIT. Due to the limited space in the offshore platform, the PIR must be sized according to its operation duty cycle so as to limit the energy dissipated during the PIT, for example, maximum three operations in $10 \mathrm{~s}$ and then $30 \mathrm{~min}$ off for cooling. With that in consideration, values of $100 \Omega 0.1 \mathrm{~s}$ for the PIR and PIT, respectively, may be a better compromise between voltage dip and required platform space in this particular case.

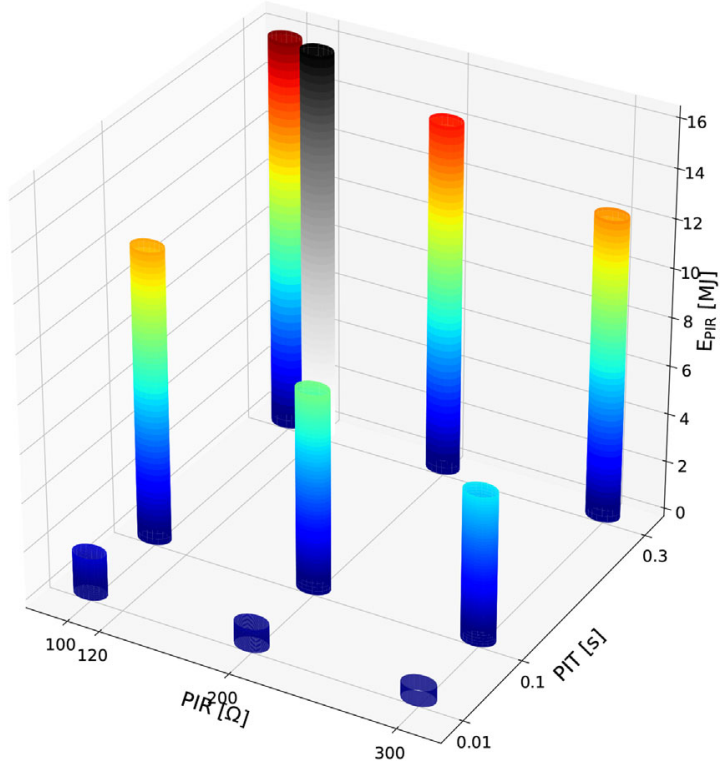

FIGURE 8 Energy dissipated by PIRs of different values during different PITs. The grey bar corresponds to PIR $=120 \Omega$ and PIT $=0.3 \mathrm{~s}$ used in [16]

TABLE 4 Transient WPP active power output peak, $P_{2}^{\text {peak }}$, in per unit (base value: $400 \mathrm{MW}$ ), for different values of time to ramp-up voltage from 0 to $1 \mathrm{pu}, t_{\text {ramp }}$

\begin{tabular}{ll}
\hline$t_{\text {ramp }}(\mathrm{s})$ & $P_{2}^{\text {peak }}(\mathrm{pu})$ \\
\hline 0.5 & 0.17 \\
1 & 0.09 \\
2 & 0.05 \\
\hline
\end{tabular}

\subsection{2 | Soft start}

Figure 7(b) shows the WPP RMS voltage, HVDC link voltage and WPP active and reactive power output for different softstart energization/voltage ramp-rates, while Table 4 compiles the corresponding active power peaks. As can be observed and expected, higher ramp rates result in higher charging active and reactive power peaks. However, even for a fast $0.5 \mathrm{~s}$ ramp to 1 pu voltage, the peak is less than $20 \%$ of the WPP rated capacity. This shows that soft-start using PEC control can in principle provide faster energization of the offshore networks while reducing the magnitude of associated transients, thus decreasing the overall restoration time and consequently the impact of a blackout. Additionally, plenty of the WPP generation capacity is left to energize auxiliary loads of other blackstart units, pick up block loads and operate stable islands before re-synchronizing with the main grid. However, low short circuit levels during energization and different settings of the under-voltage trip protection can result in delayed fault clearance and reduced selectivity for some critical faults. 


\section{5 | CONCLUSION}

Large grid-forming OWPPs could provide power system services like blackstart in the future, as the results show. The energization of the offshore network can be done using the traditionally prevalent hard-switching approach or the more complex soft-start method. However, attention should be given to the implications due to the very nature of the approaches. Hard-switching can lead to significant transients, but it provides a clear, bounded structure of the energization sequence. On the other hand, soft-start can allow a significantly faster energization process, with smaller transients, but results in delayed fault detection and clearing, with all the implications that this entails.

The simulation results corroborate that a separate controlled DC-side pre-charging stage for the onshore converter is an essential part of the energization sequence before it can be deblocked to safely control the onshore AC network voltage and allow the OWPP to stably supply the onshore block load. The sensitivity analysis conducted for hard-switching energization provides an overview of the impact of the PIR and PIT on the voltage dip and the associated energy dissipated by the PIR during the PIT. For a detailed PIR design, statistical simulations are needed to cope with the worst-case scenario. Compared to the prevailing hard-switching, the power electronics converters of the WTs enable soft-start of the offshore network elements with benefits of fast ramp-up rates and smaller smoother associated energization transients.

More studies are needed to investigate fault-related transients in soft-start energization, especially the risk of resonance excitation due to sudden post-fault voltage recovery after opening of the breaker. Furthermore, synchronization transients during the sequential energization of the WTs in a string need to be studied. Additionally, the robustness of islanded OWPP operation to events such as the sudden disconnection and re-connection of a WT, that can lead to sympathetic interaction between the transformers in the offshore collector network, also needs to be investigated.

\section{ACKNOWLEDGEMENTS}

The authors gratefully acknowledge the contributions of Ömer Göksu, Rui $\mathrm{Li}$ and $\mathrm{Lie} \mathrm{Xu}$ to the discussions leading up to this work. This work is a part of the InnoDC project that has received funding from the European Union's Horizon 2020 research and innovation programme under the Marie Skłodowska-Curie grant agreement number 765585. This work has also received funding from the European Union's Horizon 2020 research and innovation programme under grant agreement number 691714. Preliminary results have been included in the PROMOTiON Deliverable 3.7 on Compliance evaluation results using simulations (2020).

\section{ORCID}

Anubhav Jain (D) https://orcid.org/0000-0002-6264-0906 Oscar Saborio-Romano (D) https://orcid.org/0000-0001-97714955
Jayachandra N. Sakamuri (iD) https:/ / orcid.org/0000-0002-54689232

Nicolaos A. Cutululis (D) https://orcid.org/0000-0003-2438-1429

\section{REFERENCES}

1. International Energy Agency (IEA): Global Energy \& CO2 Status Report (GECO) (2019). https://www.iea.org/geco/. Accessed 25 November 2020

2. European Parliament and Council of the European Union: Directive (EU) 2018/2001 of the European Parliament and of the Council on the promotion of the use of energy from renewable sources (recast). Off. J. Eur. Union L 328, 82-209 (2018)

3. International Renewable Energy Agency (IRENA): Renewable power generation costs in 2018 (2019). https://www.irena. org/-/media/Files/IRENA/Agency/Publication/2019/May/

IRENA_Renewable-Power-Generations-Costs-in-2018.pdf. Accessed 25 November 2020

4. Wind Europe: Our energy our future: How offshore wind will help Europe go carbon-neutral (2019). https://windeurope.org/about-wind/reports/ our-energy-our-future/. Accessed 25 November 2020

5. De Boeck, S., et al.: Review of defence plans in Europe: Current status, strengths and opportunities. CIGRE Trans. Sci. Eng. 5, 6-16 (2016)

6. Australian Energy Market Operator (AEMO): Black system South Australia 28 September 2016 - Final report (2017). https://www.aemo.com.au/-/media/Files/Electricity/NEM/ Market_Notices_and_Events/Power_System_Incident_Reports/2017/ Integrated-Final-Report-SA-Black-System-28-September-2016.pdf. Accessed 25 November 2020

7. National Grid ESO: Black start from non-traditional generation technologies (2019). https://www.nationalgrideso.com/document/148201/ download

8. Jain, A., et al.: Functional requirements for blackstart and power system restoration from wind power plants'. In: 2nd International Conference on Large-Scale Grid Integration of Renewable Energy in India. Energynautics GmbH, New Delhi, India (2019)

9. Jiang.Hafner, Y., et al.: HVDC with voltage source converters: A powerful standby black start facility. In: Transmission and Distribution Exposition Conference: 2008 IEEE PES Powering Toward the Future (PIMS 2008) (2008)

10. Elia: Study on the review of the black start ancillary services (2018). https://www.elia.be/en/public-consultation/2018 1005-review-of-the-black-start-ancillary-service. Accessed 25 November 2020

11. Rocabert, J., et al.: Control of power converters in AC microgrids. IEEE Trans. Power Electron. 27(11), 4734-4749 (2012)

12. Jain, A., et al.: Control solutions for blackstart capability and islanding operation of offshore wind power plants. In: Proceedings of the 17th International Wind Integration workshop. Energynautics GmbH, Stockholm, Sweden (2018)

13. Añó.Villalba, S., et al.: Wind power plant integration in voltage source converter HVdc grids with voltage droop control. Math. Comput. Simulation 146, 186-199 (2018)

14. Martínez.Turégano, J., et al.: Mixed grid-forming and grid-following wind power plants for black start operation. In: 17th International Wind Integration Workshop. Stockholm, Sweden: Energynautics GmbH, 2018.

15. Aten, M., et al.: Dynamic simulations of a black starting offshore wind farm using grid forming converters. In: 18th Wind Integration Workshop. Energynautics GmbH, Dublin, Ireland (2019)

16. Sakamuri, J.N., et al.: Black start by HVdc-connected offshore wind power plants. In: IECON 2019-45th Annual Conference of the IEEE Industrial Electronics Society. Lisbon, Portugal (2019)

17. Sørensen, T.B., et al.: A live black start test of an HVAC network using soft start capability of a voltage source HVDC converter. In: CIGRE 2019 Aalborg Symposium. Aalborg, Denmark (2019)

18. Schyvens, T.: Interactions between transmission system connected converters. In: IEEE Power and Energy Society General Meeting. Atlanta (GA), USA (2019). Presentation 
19. Cigré, WG B3. 36: Special considerations for AC collector systems and substations associated with Hvdc-connected wind power plants. CIGRE Technical Brochure 612 (2015)

20. Sidhu, T.S., et al.: Protection issues during system restoration. IEEE Trans. Power Del. 20(1), 47-56 (2005)

21. Turner, R.A., Smith, K.S.: Transformer inrush currents. IEEE Ind. Appl. Mag. 16(5), 14-19 (2010)

22. Nagahama, N., et al. Transformer overvoltages and countermeasures during blackstart'. In: 2003 IEEE Bologna Power Tech Conference Proceedings, vol. 2. Bologna, Italy (2003)

23. Gomes, V., et al.: Inrush currents: One less thing to worry about; an innovative solution. In: 4th International Hybrid Power Systems Workshop. Crete, Greece (2019)

24. Arana, I., et al.: Energization of wind turbine transformers with an auxiliary generator in a large offshore wind farm during islanded operation. IEEE Trans. Power Del. 26(4), 2792-2800 (2011)

25. Kotak, P.J., Thakur, A.: Comparative analysis of point on wave switching technique \& prefluxing technique to mitigate in-rush current in three phase power transformer. Int. J. Sci. Eng. Res. 5(11), 831-836 (2014)

26. PROMOTiON WP3: Deliverable 3.7: Compliance evaluation results using simulations Part I: WPP/WTG control for Self-Start and Black Start Part II: WPP/WTG control for DRU Operation (2020). https://www.promotion-offshore.net/fileadmin/PDFs/D3. 7_Compliance_evaluation_results_using_simulations.pdf. Accessed 25 November 2020

27. Ferrer, A.D., et al.: Feedback on INELFE France-Spain HVDC project. In: CIGRE 2016 Paris Session. Paris, 2016.

28. The National HVDC Centre, Electric Power Research Institute (EPRI Europe DAC): Black Start from VSC HVDC and its impact on AC Protection Coordination' [Webcast] (2020)

29. Pérez, A.N.F., et al.: Co-simulation hardware in the loop test bench for a wind turbine: validation of a wind turbine black start capability. In: 18th Wind Integration Workshop. Energynautics GmbH, Dublin, Ireland (2019)

30. PROMOTioN, WP 3: Deliverable 3.1: Detailed functional requirements to WPPs (2016). https://www.promotion-offshore.net/fileadmin/ PDFs/D3.1_PROMOTioN_Deliverable_3.1_Detailed_functional_ requirements_to_WPPs.pdf. Accessed 25 November 2020

31. PROMOTioN, WP 3: Deliverable 3.2: Specifications of the control strategies and the simulation test cases (2017). https://www.promotion-offshore.net/fileadmin/PDFs/D3.

2_Specifications_Control_strategies_and_simulation_test_cases.pdf. Accessed 25 November 2020

32. Cigré, WG B4: 57: Guide for the development of models for HVDC converters in a HVDC grid. CIGRE Technical Brochure 604 (2014)

33. Muljadi, E., et al.: Method of equivalencing for a large wind power plant with multiple turbine representation'. In: 2008 IEEE Power and Energy Society General Meeting - Conversion and Delivery of Electrical Energy in the 21 st Century (2008)

34. Yu, L., et al.: Distributed PLL-based control of offshore wind turbine connected with diode-rectifier based HVDC systems. IEEE Trans. Power Del. 33(3), 1328-1336 (2018)

35. Shan, M., et al.: Design and laboratory test of black-start control mode for wind turbines. Wind Energy, 23(3), 763-778 (2020)

36. Cai, L., et al.: Simulation of startup sequence of an offshore wind farm with MMC-HVDC grid connection. IEEE Trans. Power Del. 32(2), 638646 (2017)

37. $\mathrm{Xu}, \mathrm{J}$, et al.: New precharge and submodule capacitor voltage balancing topologies of modular multilevel converter for VSC-HVDC applica- tion. In: 2011 Asia-Pacific Power and Energy Engineering Conference (APPEEC) (2011)

38. Das, A., et al.: A method for charging and discharging capacitors in modular multilevel converter. In: IECON 2011-37th Annual Conference of the IEEE Industrial Electronics Society, pp. 1058-1062. IEEE (2011)

39. Shi, K., et al.: A novel start-up scheme for modular multilevel converter. 2012 IEEE Energy Conversion Congress and Exposition (ECCE) (2012)

40. Zhang, L., et al.: A generalized precharging strategy for soft startup process of the modular multilevel converter-based HVDC systems. IEEE Trans. Ind. Appl. 53(6), 5645-5657 (2017)

41. Yu, Y., et al.: Pre-charging control strategies of modular multilevel converter. In: 2013 International Conference on Electrical Machines and Systems (ICEMS) (2013)

42. Li, B., et al.: Closed-loop precharge control of modular multilevel converters during start-up processes. IEEE Trans. Power Electron 30(2), 524-531 (2015)

43. Shi, X., et al.: Modeling, control design, and analysis of a startup scheme for modular multilevel converters. IEEE Trans. Indus. Electron. 62(11), 7009-7024 (2015)

How to cite this article: Jain A, Saborío-Romano O, Sakamuri JN, Cutululis NA. Blackstart from HVDC-connected offshore wind: Hard versus soft energization. IET Renew Power Gener. 2021;15:127-138. https://doi.org/10.1049/rpg2.12010

\section{APPENDIX A}

TABLE A1 Main circuit parameters

\begin{tabular}{ll}
\hline Parameters & Values \\
\hline WT rating & $8 \mathrm{MW}$ \\
WT GSC Filter & $L_{\mathrm{f}}=10 \%, C_{\mathrm{f}}=5 \%$ \\
WT transformer & $0.69 / 66 \mathrm{kV}$ \\
& $R=1 \%, X_{\mathrm{L}}=1 \%$ \\
WPP rating & $400 \mathrm{MW}$ \\
HVDC transformers & $1200 \mathrm{MVA}, X_{\mathrm{L}}=15 \%$ \\
& $\mathrm{~T} 2: 66 / 390 \mathrm{kV}$ \\
& $\mathrm{T} 1: 390 / 400 \mathrm{kV}$ \\
HVDC link & $\pm 320 \mathrm{kV}, 1200 \mathrm{MW}, 200 \mathrm{~km}$ \\
MMC & $1200 \mathrm{MVA}$ \\
& $225 \mathrm{submodules} \mathrm{per} \mathrm{arm}$ \\
Onshore load & $30 \mathrm{MW}$ \\
\hline
\end{tabular}

Note. T1, onshore; $\mathrm{T} 2$, offshore; $X_{\mathrm{L}}$, leakage reactance. 